\title{
Anti-tumor and anti-invasion effects of a combination of 4-methylumbelliferone and ionizing radiation in human fibrosarcoma cells
}

\author{
RYO SAGA ${ }^{1}$, SATORU MONZEN ${ }^{1}$, MITSURU CHIBA ${ }^{2}$, HIRONORI YOSHINO ${ }^{1}$, \\ TOSHIYA NAKAMURA ${ }^{2}$ and YOICHIRO HOSOKAWA ${ }^{1}$ \\ Departments of ${ }^{1}$ Radiological Life Sciences and ${ }^{2}$ Biomedical Sciences, Division of Medical Life Sciences, \\ Hirosaki University Graduate School of Health Sciences, Hirosaki, Aomori 036-8564, Japan
}

Received July 25, 2015; Accepted October 3, 2016

DOI: $10.3892 / \mathrm{ol} .2016 .5385$

\begin{abstract}
Hyaluronan (HA) is a major component of the extracellular matrix that is synthesized in excess in cancer tissues. 4-methylumbelliferone (MU) inhibits the synthesis of $\mathrm{HA}$ and is closely related to the invasion and metastasis of cancer. However, the effects of MU in conjunction with cancer radiotherapy remain unknown. The present study assessed the anti-tumor and anti-invasion effects of the concomitant use of ionizing radiation (IR) and $100 \mu \mathrm{M}$ MU on human fibrosarcoma HT1080 cells. Cell viability and cellular invasion potency assays were performed. There was a greater decrease in the viability of cells cultured with a combination of 2 Gy IR and MU compared with untreated control cells. In addition, cell cycle distribution analysis demonstrated that a higher proportion of these cells were in the sub-G1 phase and higher fractions of annexin- $\mathrm{V}$ positive, propidium iodide positive cells (i.e., apoptotic cells) were observed. HA concentration in the $2 \mathrm{~Gy}$ irradiated culture was similar to that in the non-irradiated control culture, however, it significantly decreased following the administration of both MU alone and 2 Gy IR with MU. Furthermore, treatment with 2 Gy IR and MU resulted in a significant decrease in the invasion rate and matrix metalloproteinase (MMP)-2 and MPP-9 expression. Taken together, these results suggest that the administration of MU with 2 Gy IR is effective at reducing HA production, cell invasion and the metastatic potential of cancer cells.
\end{abstract}

Correspondence to: Dr Satoru Monzen or Professor Yoichiro Hosokawa, Department of Radiological Life Sciences, Division of Medical Life Sciences, Hirosaki University Graduate School of Health Sciences, 66-1 Hon-cho, Hirosaki, Aomori 036-8564, Japan E-mail: monzens@hirosaki-u.ac.jp

E-mail: hosokawa@hirosaki-u.ac.jp

Key words: radiotherapy, 4-methylumbelliferone, hyaluronic acid, cellular invasion, human fibrosarcoma

\section{Introduction}

External radiotherapy for primary solid tumors is generally effective as it is non-invasive and improves local control in the target region. However, certain dispersal targets in radiotherapy induce poor prognosis, including distant metastasis and radiation resistance, in human fibrosarcoma HT1080 cells (1). Thus, research has focused on the metastasis-inducible factor hyaluronan (HA) to resolve these concerns pertaining to radiotherapy. $\mathrm{HA}$ is the primary component of the extracellular matrix and may promote cellular motility by activating the epidermal growth factor receptor through Akt phosphorylation signaling (2). In addition, HA regulates the expression of matrix metalloproteinases (MMP)-2 and -9, which belong to the type IV collagenase family (3). A previous report has clarified that the mutant overexpression of MMP-2 and -9 promotes distant metastasis and invasion (4). An inhibitor of HA synthesis, 4-methylumbelliferone (MU), was identified as a possible countermeasure in prostate, lung and breast cancer cell models (5-7). To the best of our knowledge, there have been no published studies investigating the administration of MU in conjunction with the exposure of cancer cells to ionizing radiation (IR); however, the chemotherapy drugs cisplatin and paclitaxel have been clinically used along with radiotherapy in various solid tumors (8-10).

It was hypothesized that if the mechanism underlying the synergistic anti-tumor effect of IR with MU was clarified, a novel countermeasure to distant metastases may be proposed. Therefore, in the present study, the effect of the administration of MU with IR on cell survival fraction, HA synthesis, and MMP expression was analyzed in HT1080 cells.

\section{Materials and methods}

Reagents. MU, an HA inhibitor, was purchased from Nacalai Tesque, Inc., (Kyoto, Japan) and diluted in dimethyl sulfoxide (DMSO; Wako Pure Chemical Industries, Ltd., Osaka, Japan). A Gelatin Zymography kit for detecting MMP was purchased from Cosmo Bio Co., Ltd., (Tokyo, Japan). The Hyaluronan Quantikine ${ }^{\circledR}$ ELISA kit for quantifying HA concentration was purchased from R\&D Systems, Inc., (Minneapolis, MN, USA). 
Cell culture. Human fibrosarcoma HT1080 cells were purchased from the American Type Culture Collection (Manassas, VA, USA) and cultured in RPMI 1640 medium (Thermo Fisher Scientific, Inc., Waltham, MA, USA) supplemented with $10 \%$ heat-inactivated fetal bovine serum (Japan Bio Serum, Fukuyama, Japan) and $1 \%$ penicillin/streptomycin (Thermo Fisher Scientific, Inc.) at $37^{\circ} \mathrm{C}$ in a humidified atmosphere with $5 \% \mathrm{CO}_{2}$. The number of viable cells was counted using the trypan blue (Sigma-Aldrich, St. Louis, MO, USA) dye exclusion method. The clonogenic potency of cells was estimated by colony formation assay and appropriate numbers of cells were seeded. Following 8-10 days of incubation, the cell colonies were fixed with methanol, stained with Giemsa (both Wako Pure Chemical Industries, Ltd.) and counted.

Exposure of cells to IR. IR was performed using an X-ray generator (MBR-1520R-3; Hitachi Medical Co. Ltd., Tokyo, Japan) with $0.5 \mathrm{~mm}$ aluminum and $0.3 \mathrm{~mm}$ copper filters at a distance of $45 \mathrm{~cm}$ between the focus and the target. Radiation was carried out at $150 \mathrm{kV}, 20 \mathrm{~mA}, 0.9 \mathrm{~Gy} / \mathrm{min}$. During X-ray exposure, the total dose and dose rate were monitored with a thimble ionization chamber placed next to the sample.

Analysis of viable and apoptotic cells. The viability of each cell culture was assessed using an annexin $\mathrm{V}$ and propidium iodide (PI) staining kit (BioLegend, Tokyo, Japan). The cell cycle distribution was analyzed by Hoechst 33342 staining. Fluorescence data were collected using the Cell Lab Quanta ${ }^{\mathrm{TM}}$ SC MPL Flow Cytometer (Beckman Coulter, Inc., Brea, CA, USA).

Invasion assay. Invasion potential was evaluated using a BioCoat Matrigel invasion chamber (BD Biosciences, San Jose, CA, USA). The HT1080 cell suspension $\left(2.5 \times 10^{4}\right.$ cells $)$ was added to 24-well chambers and incubated for $22 \mathrm{~h}$ at $37^{\circ} \mathrm{C}$ in a humidified tissue culture incubator at $37^{\circ} \mathrm{C}$ with $5 \%$ $\mathrm{CO}_{2}$. Invasive cells were fixed and stained using a Diff-Quik staining kit (Dade Behring, Inc.; Siemens Healthcare GmbH, Erlangen, Germany). The number of cells in a predetermined field of view (876x659 $\mu \mathrm{m})$ were counted, allowing a calculation of the invasion rate to be performed using the formula: Invasion rate $=$ (number of invasion cells) $/$ (number of migrated cells) x 100 .

$H A$ density quantitation. The Hyaluronan Quantikine ${ }^{\circledR}$ ELISA kit (R\&D Systems, Inc.) was used to analyze the HA concentration of the supernatants. At near confluence, $30 \mu \mathrm{l}$ aliquots of the HT1080 cell culture supernatants were prepared, and $210 \mu \mathrm{l}$ aliquots of the Calibrator Diluent RD5-18 buffer was added to the kit. The samples were subsequently added and buffer from the kit (HA conjugate and substrate solution) was added to each well. Finally, stop solution was added, and the absorbance of each well was measured at a wavelength of $540 \mathrm{~nm}$ using a microplate reader (10043; Bio-Rad Laboratories, Inc., Hercules, CA, USA). HA concentration was calculated from a standard curve of the measured absorbance.

MMP protein and gene expression analysis. Reverse transcription-quantitative polymerase chain reaction (RT-qPCR) was performed to quantify MMP mRNA expression. Total RNA was extracted from HT1080 cells using an RNeasy ${ }^{\circledR}$ Micro kit (Qiagen, Inc., Valencia, CA, USA) and quantified using a NanoDrop Spectrophotometer (NanoDrop Technologies; Thermo Fisher Scientific, Inc., Wilmington, DE, USA). First strand cDNAs were synthesized using the iScript ${ }^{\mathrm{TM}}$ cDNA $^{\mathrm{T}}$ Synthesis kit (Bio-Rad Laboratories, Inc.) according to the manufacturer's instructions. The expression of MMP-2, -9 and GAPDH were measured by RT-qPCR using the TaqMan ${ }^{\circledR}$ assay (Applied Biosystems; Thermo Fisher Scientific., Inc.) with Hs01548727_m1 for MMP-2, Hs0095755_m1 for MMP-9, and Hs99999905_m1 for GAPDH. RT-qPCR was performed using the StepOnePlus ${ }^{\mathrm{TM}}$ Real-Time PCR system (Applied Biosystems; Thermo Fisher Scientific., Inc.) under the conditions of $10 \mathrm{~min}$ at $95^{\circ} \mathrm{C}$, followed by 40 cycles at $95^{\circ} \mathrm{C}$ for $15 \mathrm{sec}$ and $60^{\circ} \mathrm{C}$ for $60 \mathrm{sec}$. Relative differences in expression were determined by the $\Delta \Delta \mathrm{Cq}$ method. GAPDH was used as an internal control for each reaction and the mRNA expression of the control was defined as the baseline.

The extracellular protein expression of MMP-2 and -9 were measured using the Gelatin Zymography protease assay kit (Cosmo Bio Co., Ltd.). At near confluence, $70 \mu \mathrm{l}$ supernatant of serum-free cell culture was mixed with $30 \mu \mathrm{l}$ sample buffer [8.7\% sodium dodecyl sulfate ( $\mathrm{SDS}$ ); 0.5 M Tris- $\mathrm{HCl}$ (pH 6.8), $70 \%$ glycerol and $0.05 \%$ bromophenol blue] and loaded on the gel. Prepared samples were then subjected to electrophoresis on $10 \%$ SDS-polyacrylamide gels containing $0.417 \%$ gelatin. Following electrophoresis, the gels were washed in $2.5 \%$ Triton $\mathrm{X}-100$ for $1 \mathrm{~h}$ at room temperature to remove SDS. The gels were subsequently incubated at $37^{\circ} \mathrm{C}$ for $18 \mathrm{~h}$ in a substrate buffer containing $50 \mathrm{mM}$ Tris- $\mathrm{HCl}(\mathrm{pH} 7.5)$ and $10 \mathrm{mM} \mathrm{CaCl}_{2}$ and stained with $0.25 \%$ Coomassie Brilliant Blue R250 in $45 \%$ methanol and $10 \%$ acetic acid. The section of the substrate degraded by proteases was detected as clear bands. The band sizes were determined by gel densitometry using the program ImageJ ver. 1.44b (National Institutes of Health, Bethesda, MD, USA).

Statistical analysis. The significance of the differences between the control and experimental cultures was determined using the Tukey-Kramer test. Statistical analysis was performed using Microsoft Excel 2010 (Microsoft Corporation, Redmond, WA, USA) with the add-on software Statcel (version 3; OMS Publishing, Inc., Saitama, Japan). $\mathrm{P}<0.05$ was considered to indicate a statistically significant difference. Dose survival curves were fitted using the Boltzmann function.

\section{Results}

Cell viability following $M U$ and X-irradiation. MU was dissolved in DMSO prior to being added to the cell culture medium. Cells cultured with $0.1 \%$ DMSO were considered controls as the viability of HT1080 and WI38 cells (non-cancer fibroblast cells) with $0.1 \%$ DMSO added to the cell culture medium was similar to that of untreated cells. To clarify the toxicity of the MU concentration, HT1080 and WI38 cells were cultured with DMSO containing MU. The survival fraction of HT1080 cells in $>100 \mu \mathrm{M}$ MU decreased significantly $\left(100 \mu \mathrm{M}, 0.3 \pm 0.1 ; 200 \mu \mathrm{M}, 8.0 \pm 0.4 \times 10^{-2}\right)$ compared to WI38 cells $(100 \mu \mathrm{M}, 1.1 \pm 0.2 ; 200 \mu \mathrm{M}, 1.0 \pm 0.2$; Fig. 1A), indicating that they were more sensitive to MU. The 

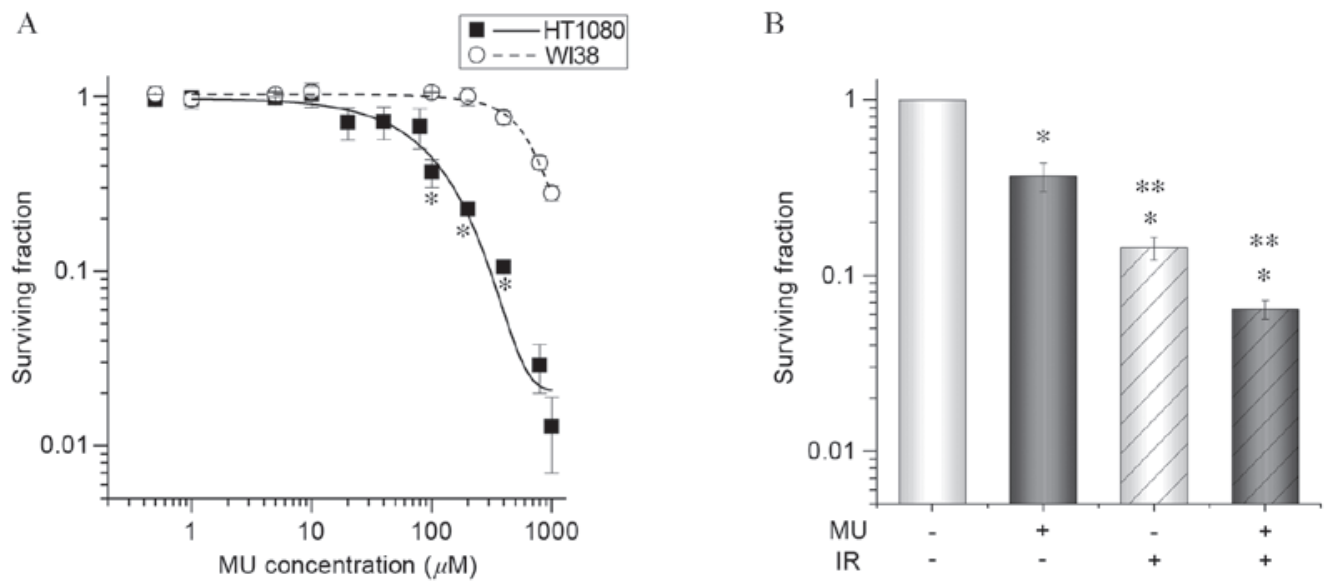

Figure 1. Clonogenic potency assay. (A) The toxicity curves of HT1080 and WI38 cells treated with MU (dose, 0-1000 $\mu$ M) were completed using the colony formation method and the number of colonies were counted 10 days following culture initiation. (B) The surviving fraction of clonogenic cells in HT1080 cells treated with $100 \mu \mathrm{M} \mathrm{MU}$ and/or 2 Gy IR were analyzed. Values are presented as the mean \pm standard error of the mean. ${ }^{*} \mathrm{P}<0.01 \mathrm{vs}$. control, ${ }^{* *} \mathrm{P}<0.01 \mathrm{vs}$. $100 \mu \mathrm{M}$ MU alone. MU, 4-Methylumbelliferone; IR, ionizing radiation.

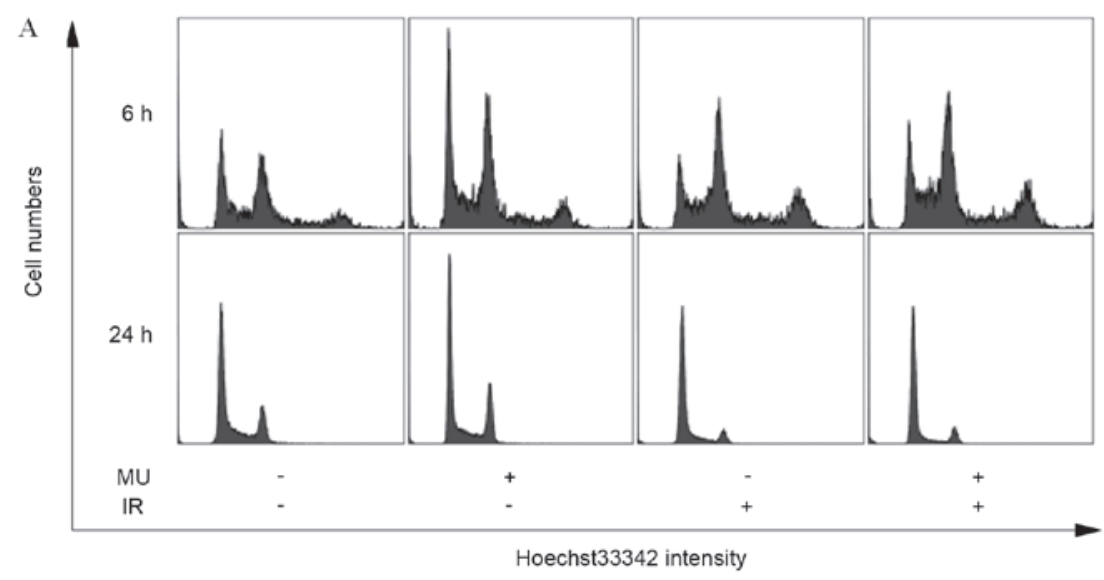

B Sub-G1 phase
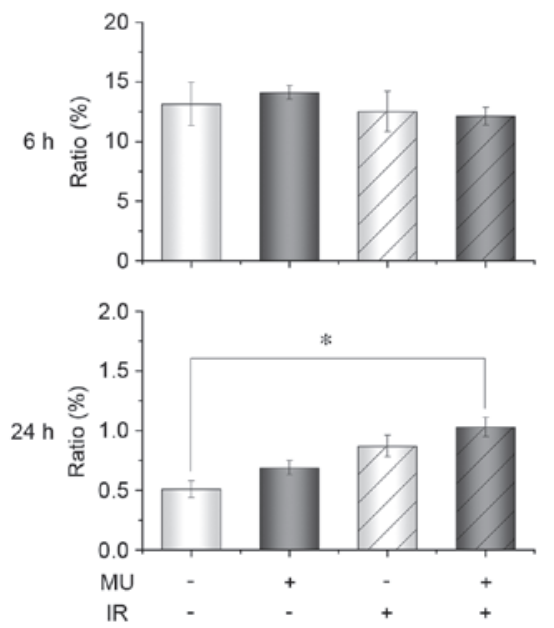

C G2/M phase
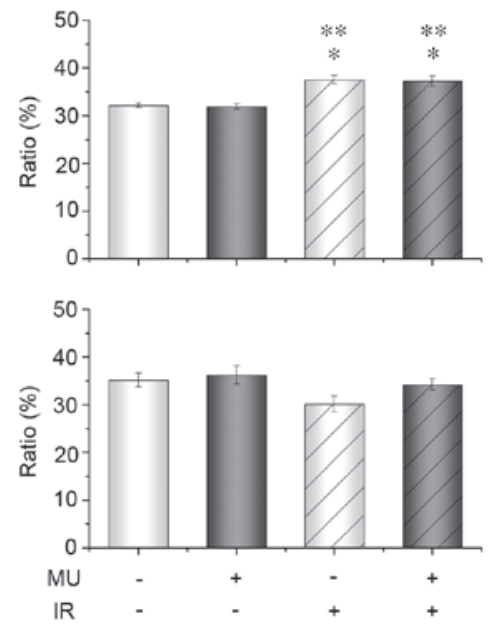

Figure 2. Flow cytometric patterns for the cell cycle. HT1080 cells treated with $100 \mu \mathrm{M}$ MU and/or 2 Gy IR were cultured for 6 and 24 h. (A) A representative cytogram and quantitative analysis. The percentage of cells in the (B) sub-G1 phase and (C) G2/M phase are presented. Values are presented as mean \pm standard error of the mean. ${ }^{*} \mathrm{P}<0.05$ vs. control and ${ }^{* *} \mathrm{P}<0.05$ vs. MU without 2 Gy IR. MU, 4-Methylumbelliferone; IR, ionizing radiation.

lowest effective concentration, $100 \mu \mathrm{M}$ MU, was chosen to evaluate the effect of MU with 2 Gy IR due to its specificity for tumor cells.
A clonogenic potency assay was conducted to examine the effect of $100 \mu \mathrm{M}$ MU with 2 Gy IR on HT1080 cells (Fig. 1B). There was a significantly greater decrease $\left(3.6 \pm 0.7 \times 10^{-1}\right)$ in the 
A

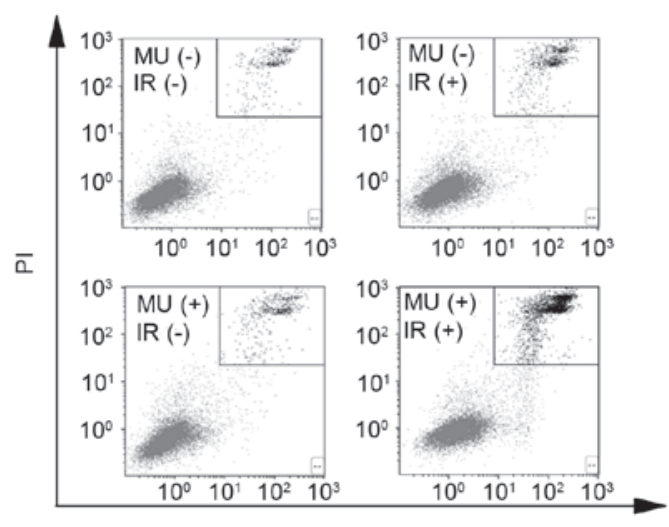

Annexin V

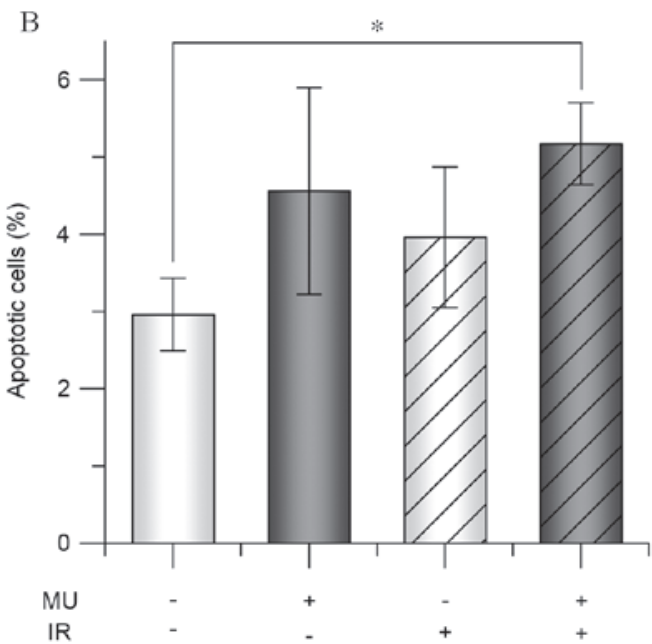

Figure 3. Analysis of apoptotic cell fraction by concurrent staining with annexin-V and PI. HT1080 cells treated with $100 \mu \mathrm{M}$ MU and/or 2 Gy IR were cultured for $24 \mathrm{~h}$. (A) A representative cytogram and (B) quantitative analysis of cell fractions are presented. Values are provided as the mean \pm standard error of the mean. "P<0.05 vs. control. PI, propidium iodide; MU, 4-Methylumbelliferone; IR, ionizing radiation.

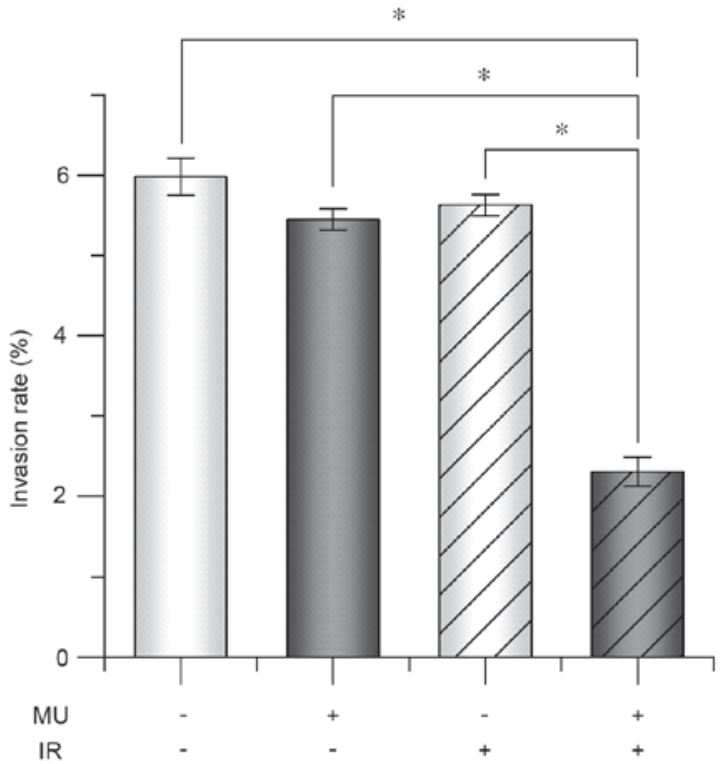

Figure 4. Analysis of cell invasion potency. Invasion rates of HT1080 cells cultured with $100 \mu \mathrm{M}$ MU and/or 2 Gy IR for $24 \mathrm{~h}$ were analyzed using a BioCoat Matrigel invasion chamber. Values are provided as the mean \pm standard error of the mean. "P<0.01. MU, 4-Methylumbelliferone; IR, ionizing radiation.

survival of cells treated with $100 \mu \mathrm{M}$ MU decreased compared with controls (no decrease; Fig. 2B). Furthermore, in cells treated with $100 \mu \mathrm{M}$ MU and 2 Gy IR, there was a significantly greater decrease $\left(6.4 \pm 0.8 \times 10^{-2}\right)$ in cell survival compared with cells treated with 2 Gy IR or MU alone. These results indicate that MU with $2 \mathrm{~Gy} \mathrm{IR}$ is a more effective anti-tumor treatment than 2 Gy IR alone.

To clarify whether the decrease in cell survival occurred by cell death and/or quiescence, cell cycle distribution and apoptosis markers were assessed. Following 2 Gy IR and MU treatment, there was a significant increase of the number of cells in the G2/M phase of the cell cycle after $6 \mathrm{~h}$ (control, $32.2 \pm 0.5 \%$; 2 Gy IR, $37.6 \pm 0.9 \%$; 2 Gy IR and MU, 37.3 $\pm 1.1 \%$ ) and in the sub-G1 phase after $24 \mathrm{~h}$ (control, $0.5 \pm 0.1 \% ; 2$ Gy IR

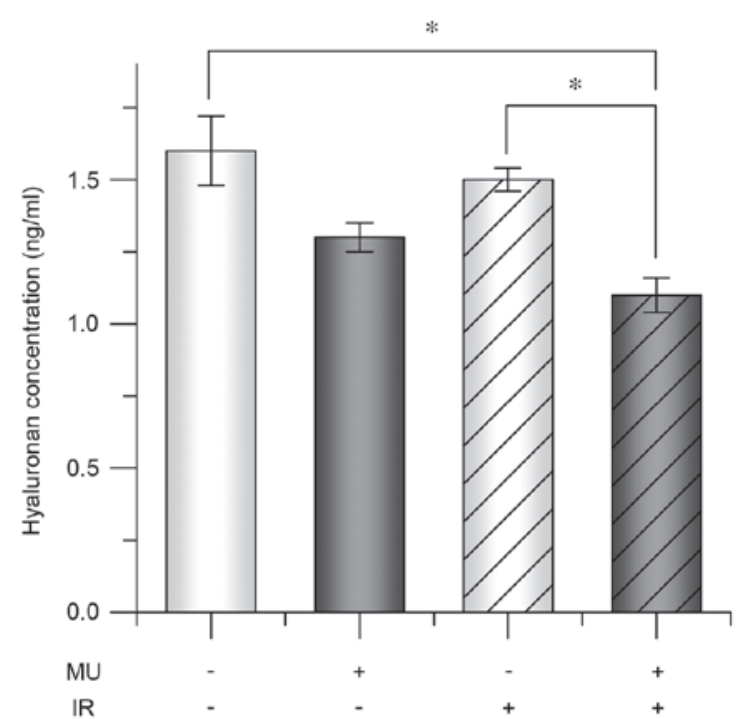

Figure 5. Quantitative analysis of hyaluronan concentration. The cell culture supernatants of HT1080 cells cultured with $100 \mu \mathrm{M}$ MU and/or 2 Gy IR for $24 \mathrm{~h}$ were collected and quantified by an enzyme-linked immunosorbent assay. Values are presented as the mean \pm standard error of the mean. ${ }^{*} \mathrm{P}<0.01$. MU, 4-Methylumbelliferone; IR, ionizing radiation.

and MU, $1.0 \pm 0.1 \%$; Fig. 2). Furthermore, there was a significant increase of the fraction of annexin- $\mathrm{V}(+), \mathrm{PI}(+)$ cells, following 2 Gy IR and MU treatment $(5.2 \pm 0.5 \%)$ compared with the control (3.0 $0.5 \%$; Fig. 3), indicating increased apoptosis. The results from cells treated with $4 \mathrm{~Gy}$ were similar to that of cells treated with 2 Gy (data not shown).

Analysis of cell invasion potential. To verify invasion at a cellular level, the potential invasion rate was quantified. The invasion rate of cells treated with 2 Gy IR and MU was significantly lower $(2.3 \pm 0.4 \%)$ than that of the control $(6.0 \pm 0.6 \%$; Fig. 4). To evaluate the extracellular environment under 2 Gy IR with $100 \mu \mathrm{M} \mathrm{MU}, \mathrm{HA}$ concentrations were analyzed in the culture supernatants. The HA concentration of control HT1080 cells $\left(1.0 \times 10^{5}\right.$ cells) was $1.5 \pm 0.2 \times 10^{2} \mathrm{ng} / \mathrm{ml}$ after $24 \mathrm{~h}$ 
A MMP2 mRNA

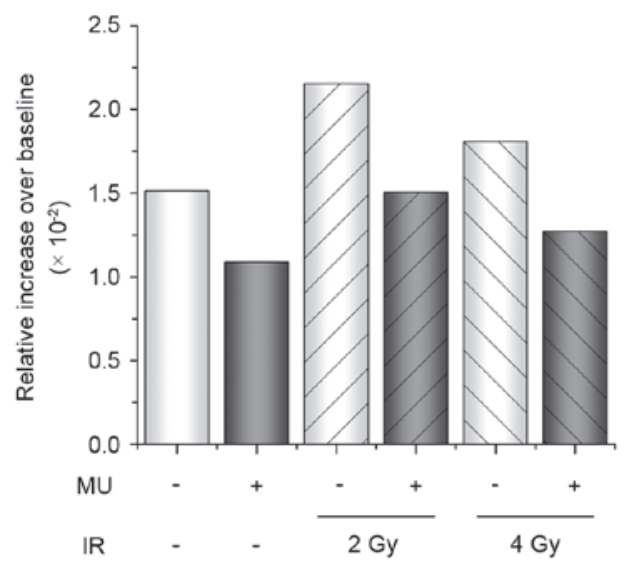

C Bands of MMPs

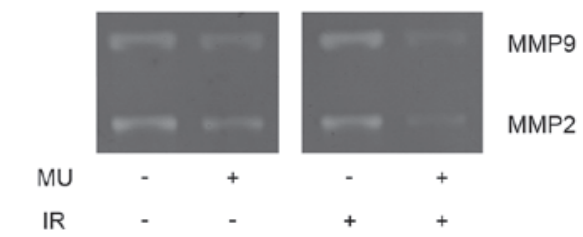

D MMP2 protein

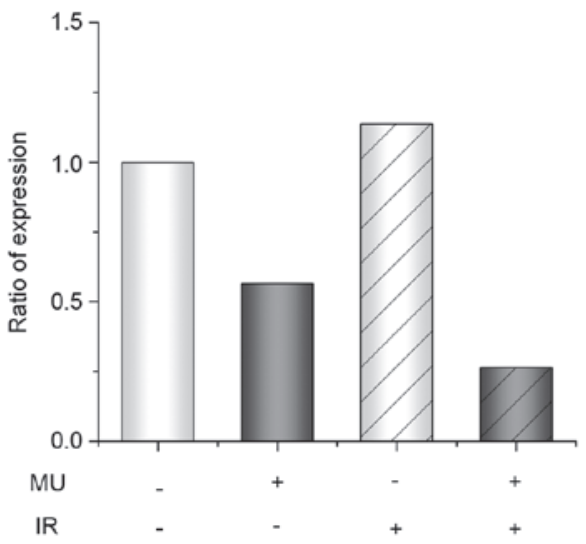

B MMP9 mRNA

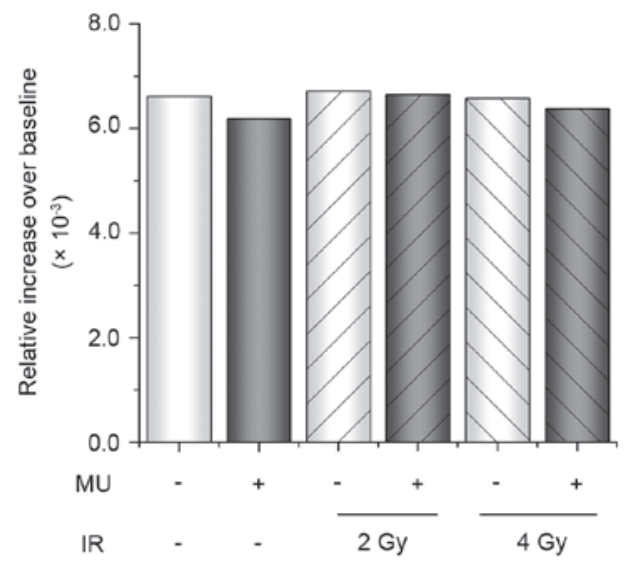

E MMP9 protein

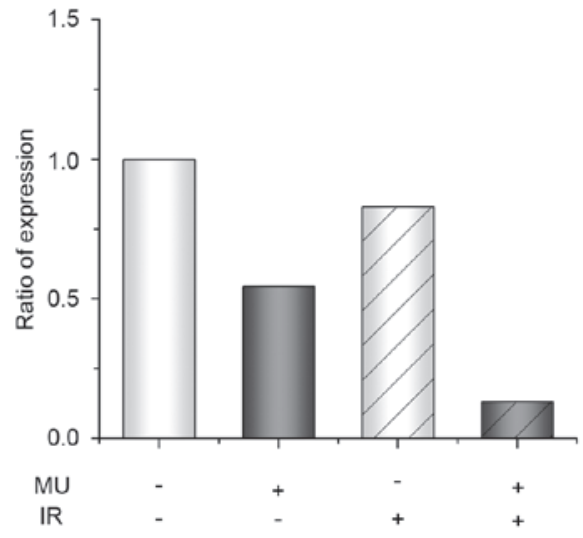

Figure 6. Expression of MMP-2 and -9. (A) MMP-2 and (B) -9 mRNA expression was analyzed using reverse transcription-quantitative polymerase chain reaction in HT1080 cells incubated for $24 \mathrm{~h}$ following administration of $100 \mu \mathrm{M}$ MU and/or 2 or 4 Gy IR. The values presented are the means of 3 separate experiments. The protein expression of MMP-2 and -9, including cell culture supernatants of HT1080 cells cultured with $100 \mu \mathrm{M}$ MU and/or 2 Gy IR for $24 \mathrm{~h}$, were collected and assayed by gelatin zymography. The bands obtained using (C) electropherogram and quantitative values of typical samples of (D) MMP-2 and (E) MMP-9 are presented. MU, 4-Methylumbelliferone; MMP, matrix metalloproteinase.

and was similar in cells treated with MU or 2 Gy IR alone (MU, $1.3 \pm 0.1 \times 10^{2} \mathrm{ng} / \mathrm{ml} ; 2$ Gy IR, $1.4 \pm 0.1 \times 10^{2} \mathrm{ng} / \mathrm{ml}$; Fig. 5). However, HA concentration following 2 Gy IR treatment with MU was significantly lower $\left(1.1 \pm 0.1 \times 10^{2} \mathrm{ng} / \mathrm{ml}\right)$ compared with the control and other treatments (Fig. 5).

Expression of MMPs. The expression of MMP-2 and -9, an indication of cell invasion, were analyzed in cells exposed to 2-4 Gy IR with or without MU. A higher expression of MMP-2 mRNA following 2 and 4 Gy IR was observed compared with the control (Fig. 6A). However, the addition of MU suppressed the expression of MMP-2 mRNA (Fig. 6A). A similar expression of MMP-9 mRNA following treatment with 2 Gy IR and/or MU was observed the control (Fig. 6B). However, the expression of MMP protein in the culture supernatant was strongly suppressed following 2 Gy IR with MU, compared with the control and other treatments (Fig. 6C-E).

\section{Discussion}

Previous studies in prostate and breast cancer cells have reported that the anti-tumor effect of MU may be due to the inhibition of cell proliferation and apoptosis induction $(5,7)$. Furthermore, it has been demonstrated that $1.0 \mathrm{mM} \mathrm{MU}$ exerts its anti-tumor effect on ovarian cancer by suppressing thymidine phosphorylase expression (11). In another study, Saito et al (12) indicated that MU leads to growth arrest and apoptosis mediated by BAX expression and a reduction in HA 
synthesis. In the present study, the induction of apoptosis by MU in HT1080 cells was observed, suggesting that the intracellular signaling pathway of apoptosis affected by $100 \mu \mathrm{M}$ MU and is not dependent on the type of tumor. By contrast, combining 2 Gy IR with MU in fibroblast cells exerted a stronger anti-cell proliferation effect that is specific to cancer without being toxic to normal cells. To the best of our knowledge, this is novel information that has not yet been reported.

It has been demonstrated that IR produces reactive oxygen species (ROS) or free radicals, including X-rays and $\gamma$-rays that indirectly and/or directly induce DNA strand breakage and exert various cytotoxic effects $(13,14)$. Braga et al $(15)$ reported previously that HA has antioxidant activity, therefore, it was suggested that the reduction in HA concentration by MU observed in the current study increases the accumulation of oxidative stress and DNA damage by 2 Gy IR.

It is important to control invasion and metastasis when treating cancer, however, this has not yet been achieved. A highly potent invasive tumor exhibits aberrant secretion of HA and overexpression of cluster of differentiation 44 antigen, which acts as the HA receptor (16). HA is produced from injured tissue stroma and is rapidly deposited in the extracellular matrix, where it regulates repair processes through cross-talk with various inflammatory conditions, including carcinogenesis (17). Abnormal secretion of HA has been observed in malignant tumors (18), however, HA is required in normal tissue, therefore, it is important to clarify the regulating system for HA secretion. Kim et al (19) have reported that suppression of MMP-9 activity and vascular endothelial growth factor production in malignant tumor cells reduces tumor metastasis and angiogenic potency. In addition, Rauhala et al (20) have demonstrated that keratinocytes exposed to low-dose UVB radiation increased HA synthesis with the production of ROS. Fibrosarcoma is known as the radioresistant cell (21), which may be related to the induction of HA synthesis by radiation.

Previous studies have demonstrated that gene expression of MMP-2 and -9 is upregulated following IR and is associated with cellular invasion (22). The results of the current study regarding mRNA expression following treatment with 2 Gy and 4 Gy differed in comparison with previous reports. In the current study, the levels of MMP protein significantly decreased following 2 Gy IR with MU (Fig. 6C-E). However, direct comparison of these results may not be possible as the previous reports do not include clear information regarding dose rate and radiation energy.

The regulation of ROS and HA synthesis may be required in fibrosarcoma treatment. The current study presents evidence that a combination of IR with MU is able to inhibit invasion potency and this may be a potential cancer treatment for radioresistant tumors in the case of HA overexpression. Further elucidation and a biological model analysis of the association between radiosensitive tumors and HA synthesis is required in the future.

In conclusion, the present study investigated the effect of combining MU with external radiotherapy as an anti-tumor treatment. Cell viability, extracellular HA concentration and cellular invasion potential in HT1080 cells treated with 2 Gy IR and MU were analyzed. A decrease in HA concentration, invasion rate and expression of MMP-2 and -9 following treatment of 2 Gy IR with MU was observed, along with suppression of clonogenic potential compared with non-treated cells. These results suggest that a combination of 2 Gy IR and MU has a synergic effect as an anti-invasion treatment and significant anti-tumor and -invasion effects in HT1080 cells and thus may be developed for clinical use as an inhibitor of distant metastasis in radiation therapy.

\section{Acknowledgements}

The present study was supported by the Japan Society for the Promotion of Science KAKENHI (Tokyo, Japan) Scientific Research and Young Scientist Grants (grant nos. 24591831 and 25861054), and the Hirosaki University Institutional Research Grant (Hirosaki, Japan; grant no. 2014).

\section{References}

1. Zagars GK, Ballo MT, Pisters PW, Pollock RE, Patel SR, Benjamin RS and Evans HL: Prognostic factors for patients with localized soft-tissue sarcoma treated with conservation surgery and radiation therapy: An analysis of 1225 patients. Cancer 97: 2530-2543, 2003.

2. Hiraga T, Ito $\mathrm{S}$ and Nakamura $\mathrm{H}$ : Cancer stem-like cell marker CD44 promotes bone metastases by enhancing tumorigenicity, cell motility, and hyaluronan production. Cancer Res 73: 4112-4122, 2013.

3. Duffy MJ, Maguire TM, Hill A, McDermott E and O'Higgins N: Metalloproteinases: Role in breast carcinogenesis, invasion and metastasis. Breast Cancer Res 2: 252-257, 2000.

4. Toole BP: Hyaluronan-CD44 Interactions in cancer: Paradoxes and possibilities. Clin Cancer Res 15: 7462-7468, 2009.

5. Lokeshwar VB, Lopez LE, Munoz D, Chi A, Shirodkar SP, Lokeshwar SD, Escudero DO, Dhir N and Altman N: Antitumor activity of hyaluronic acid synthesis inhibitor 4-methylumbelliferone in prostate cancer cells. Cancer Res 70: 2613-2623, 2010.

6. Arai E, Nishida Y, Wasa J, Urakawa H, Zhuo L, Kimata K, Kozawa E, Futamura N and Ishiguro N: Inhibition of hyaluronan retention by 4-methylumbelliferone suppresses osteosarcoma cells in vitro and lung metastasis in vivo. Br J Cancer 105: 1839-1849, 2011.

7. Urakawa H, Nishida Y, Wasa J, Arai E, Zhuo L, Kimata K, Kozawa E, Futamura N and Ishiguro N: Inhibition of hyaluronan synthesis in breast cancer cells by 4-methylumbelliferone suppresses tumorigenicity in vitro and metastatic lesions of bone in vivo. Int J Cancer 130: 454-466, 2012.

8. Sano D, Matsumoto F, Valdecanas DR, Zhao M, Molkentine DP Takahashi Y, Hanna EY, Papadimitrakopoulou V, Heymach J, Milas L and Myers JN: Vandetanib restores head and neck squamous cell carcinoma cells' sensitivity to cisplatin and radiation in vivo and in vitro. Clin Cancer Res 17: 1815-1827, 2011.

9. Chan AT, Leung SF, Ngan RK, Teo PM, Lau WH, Kwan WH, Hui EP, Yiu HY, Yeo W, Cheung FY, et al: Overall survival after concurrent cisplatin-radiotherapy compared with radiotherapy alone in locoregionally advanced nasopharyngeal carcinoma. J Natl Cancer Inst 97: 536-539, 2005.

10. Byun JW, Lee HS, Song SU, Lee SW, Kim SK, Kim WC, Lee MH and Choi GS: Combined treatment of murine fibrosarcoma with chemotherapy (Paclitaxel), radiotherapy, and intratumoral injection of dendritic cells. Ann Dermatol 26: 53-60, 2014.

11. Tamura R, Yokoyama Y, Yoshida H, Imaizumi $\mathrm{T}$ and Mizunuma H: 4-Methylumbelliferone inhibits ovarian cancer growth by suppressing thymidine phosphorylase expression. J Ovarian Res 7: 94, 2014.

12. Saito T, Tamura D, Nakamura T, Makita Y, Ariyama H, Komiyama K, Yoshihara T and Asano R: 4-methylumbelliferone leads to growth arrest and apoptosis in canine mammary tumor cells. Oncol Rep 29: 335-342, 2013.

13. Bajinskis A, Natarajan AT, Erixon K and Harms-Ringdahl M: DNA double strand breaks induced by the indirect effect of radiation are more efficiently repaired by non-homologous end joining compared to homologous recombination repair. Mutat Res 756: 21-29, 2013. 
14. Vignard J, Mirey G and Salles B: Ionizing-radiation induced DNA double-strand breaks: A direct and indirect lighting up. Radiother Oncol 108: 362-369, 2013

15. Braga PC, Dal Sasso M, Lattuada N, Greco V, Sibilia V, Zucca E, Stucchi L, Ferro E and Ferrucci F: Antioxidant activity of hyaluronic acid investigated by means of chemiluminescence of equine neutrophil bursts and electron paramagnetic resonance spectroscopy. J Vet Pharmacol Ther 38: 48-54, 2015.

16. Kim Y and Kumar S: CD44-mediated adhesion to hyaluronic acid contributes to mechanosensing and invasive motility. Mol Cancer Res 12: 1416-1429, 2014.

17. Briggs A, Rosenberg L, Buie JD, Rizvi H, Bertagnolli MM and Cho NL: Antitumor effects of hyaluronan inhibition in desmoid tumors. Carcinogenesis 36: 272-279, 2015.

18. Saito T, Dai T and Asano R: The hyaluronan synthesis inhibitor 4-methylumbelliferone exhibits antitumor effects against mesenchymal-like canine mammary tumor cells. Oncol Lett 5: $1068-1074,2013$
19. Kim A, Im M, Yim NH and Ma JY: Reduction of metastatic and angiogenic potency of malignant cancer by Eupatorium fortunei via suppression of MMP-9 activity and VEGF production. Sci Rep 4: 6994, 2014

20. Rauhala L, Hämäläinen L, Salonen P, Bart G, Tammi M, Pasonen-Seppänen S and Tammi R: Low dose ultraviolet B irradiation increases hyaluronan synthesis in epidermal keratinocytes via sequential induction of hyaluronan synthases Has1-3 mediated by p38 and Ca2+/calmodulin-dependent protein kinase II (CaMKII) signaling. J Biol Chem 288: 17999-18012, 2013.

21. Wei K, Kodym R and Jin C: Radioresistant cell strain of human fibrosarcoma cells obtained after long-term exposure to x-rays. Radiat Environ Biophys 37: 133-137, 1998.

22. Speake WJ, Dean RA, Kumar A, Morris TM, Scholefield JH and Watson SA: Radiation induced MMP expression from rectal cancer is short lived but contributes to in vitro invasion. Eur J Surg Oncol 31: 869-874, 2005. 